facile princeps in M. Lecoq de Boisbaudran's spectrum of the negative pole, and was therefore termed $a$ by him, though to the confounding of his series of Greek letters in the positive pole's spectrum-I wrote of it in I880 as "grand line peculiar to cyanogen," "the powerful violet line (viz. the above) at 59,405 W.N.B. inch, may become useful as a reference for place to many observers," and "grandly strong violet line, followed by a band ; specially characteristic of cyanogen."

But a better view of the testimony of the whole case will be found in the above pair of tables, in the first of which I have collected, in a rude way of my own, all the lines and bands which are supernumerary in M. Lecoq de Boisbaudran's negative, as compared with his positive, pole ; and in the second I have entered my former conclusions from gas-vacuum tube observations of what spectral lines and bands are peculiar to the compound gas cyanogen.

15, Royal Terrace, Edinburgh, July 25

\section{The Earliest Known Plotting Scale}

THE Babylonian statues recently acquired for the Louvre by the mission of $M$. de Sarzec are of great interest in the history of measurement. The earliest datable measuring rods hitherto known are two Egyptian masons' cubits of wood, of the reign of Hor-em-heb in the fifteenth century B.C. ; but on these statues we find represented not merely a mason's rod, but a finely. divided plotting scale, and the date of these figures is placed before the fifteenth century B.C. Of course the accurate lengths of cubits can easily be recovered from the dimensions of build. ings of the earliest periods; but no measures, or accurate representations of such, are preserved to us from the primitive times.

There are several of these diorite statues of King Goudea in the Louvre, some rather less and some rather more than life size; all finely executed in a style superior to anything of the later times from Mesopotamia, with which we were already familiar. They are wrought by means of tubular drills and graving tools, by which lengthy and delicate inscriptions are cut all over the surfaces; the tools employed seem to have been very similar to those used by the early Egyptians for their statuary in diorite, which I recently described at the Anthropological Institute.

The statues which now concern us are two seated figures of an architect (or perhaps the king, as founder); these each bear on the knees a drawing board, $6.3 \times 11^{\circ} 3$ and $77^{\circ} \times 12^{\circ} 7$ inches respectively. One board is plain, the other has an elaborate outline of a fortified town, showing all the buttresses and turns of the wall. By the right band of each figure lies a drawing stylus, and along the front of each board a plotting scale, subdivided along both outer and inner face.

These scales have a sloping face along each side, like modern scales, but meeting in a ridge at the top, like French plotting scales, without a level space. The breadth is ' 90 , and height 33 inch, sloping therefore about $36^{\circ}$; the length is just over Io $\frac{1}{2}$ inches, or half a cubit, the terminals being lines, with a small surplus beyond them.

The subdivisions vary on the different sides; but the general arrangement is a uniform series of spaces, which we will call digits; these are each $\frac{1}{18}$ of the half cubit, or 653 inch. Then along one side of each rod the alternate digits are subdivided; thus there can be no confusion between digit lines and subdivisions. The dividing lines run the whole width of the face; they are about $\frac{1}{50}$ inch wide, and scored out nearly as deep into the diorite. The subdivisions are of halves, thirds, fourths, fifths, and sixths of a digit; and two sixths are carried over to the other side of the scale, and there further divided into twelfths and eighteenths of a digit; this last fraction being only $\frac{1}{29}$ of an inch.

By calculating a normal scale from the various digit lines (as described in "Inductive Metrology," p. 3I) the average error of division may then be computed. It is about the same for the digits and also the subdivisions, varying on different sides from '009 to 013 inch; the mean error of all the digit marks is - OII inch, or about half the breadth of a cut. But it is not to be expected that mere decorative representations like these would be divided with the same care as actual working scales. The mean value of the cubit deduced from these scales is $20.89 \pm .07$ inch, which is apparently a long variant of the old $20^{\circ} 63$ cubit, and not the later Assyrian cubit of $2 \mathrm{r}^{\circ} 4$ or $2 \mathrm{I}^{\circ} 6$.

The actual values of the divisions of the two sides of each scale are as follows, stating the amounts as differences from the normal scale in thousandths of an inch, which enables the varia- tions to be most plainly seen. The points measured were about one-third from the bottom edge toward the top ridge.

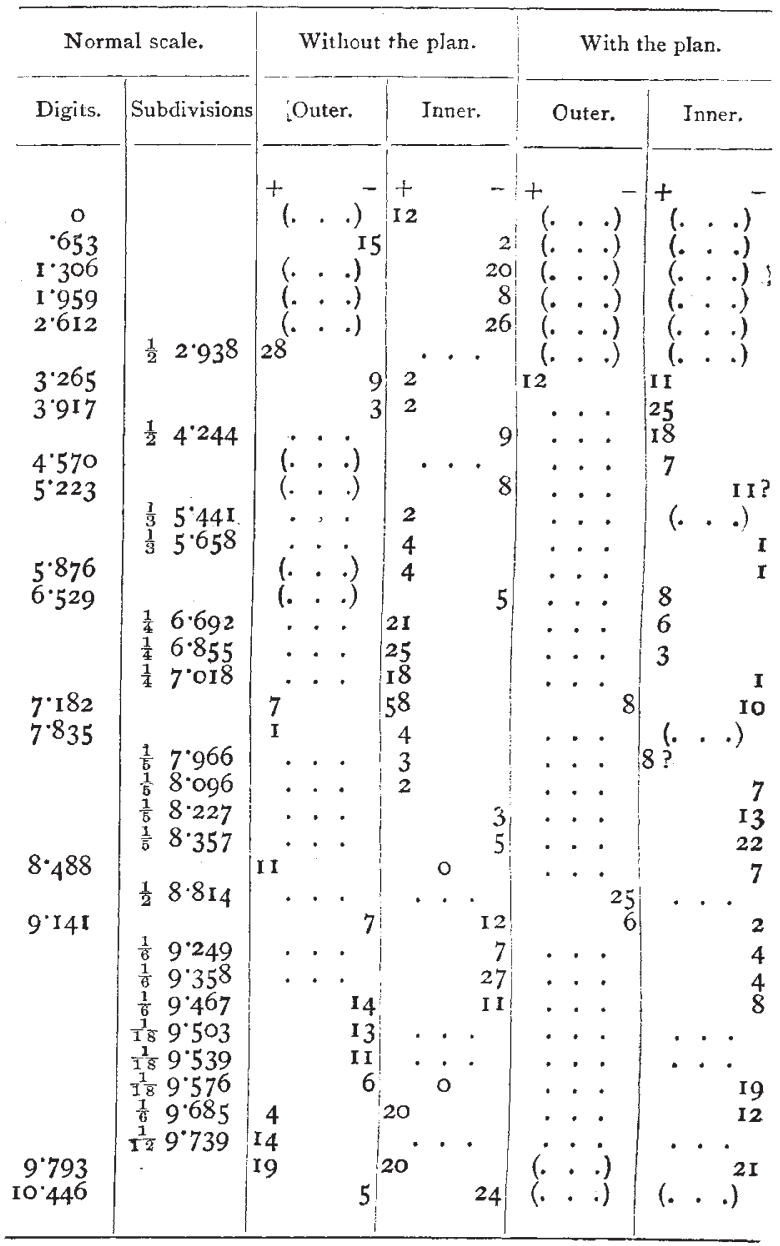

The plain dots show that there was no mark; the dots in brackets where a mark is defaced, or the whole surface destroyed. The great error of 058 inch is due to a cut run askew, the line being as accurate as the others on the outer face of the rod.

$I$ am indebted to $M$. Ledrain for kindly granting me permission to take the measurements from these statues.

Bromley, Kent

W. M. Flinders Petrie

\section{A Result of our Testimonial System}

A LitTle incident has come under my notice of such a character that $I$ think it ought to be made known to the readers of NATURE.

A candidate, whom I will call Mr. A. B., for a vacant scientific chair in this country writes to an eminent German professor for a "testimonial," and in his letter there occurs the following remarkable sentence :-

$$
\text { “... I } 7 \text { Fuly, '83 }
$$

"DEAR SIR,-I intend applying for the vacant chair of . . at ..., and would feel grateful if you could send me a testimonial saying a few favourable things of my contributions to the science of . .

". . I I hope that you will not think me too bold in asking this request, and as I know your time is too valuable to be trespassed on by a stranger, I beg that you will accept the inclosed."

The German professor, whom I will call Prof. C., thereupon writes to a distinguished English professor, who is a personal friend of his, the following letter, which has been placed in my hands with the request that I will add a few comments. The letter, which I give in its original language in order that none of its force may be lost, runs as follows :- 